\title{
A volta do filho pródigo: um entendimento sobre a teoria da Psicologia Analítica ${ }^{1}$
}

\section{The return of the prodigal son: an understanding of theory of Analytical Psychology}

\author{
Lila de Fátima de Carvalho Ramos ${ }^{2}$, Sônia Maria Bufarah Tommasi ${ }^{3}$
}

\section{Resumo}

\begin{abstract}
Este estudo tem por objetivo identificar alguns conceitos básicos da Psicologia Analítica na pintura de Rembrandt, inspirada na parábola "O filho pródigo", retirada da Bíblia - Evangelho de Lucas, capítulo XV, versículos 1-32. Consideraram-se os preceitos da Psicologia Analítica sobre individuação, consciente, inconsciente pessoal, coletivo, anima, animus, self, persona, símbolos, complexos, complexo paterno, processo de individuação, arquétipos e sua correlação com a expressão artística religiosa. A metodologia consistiu em uma revisão bibliográfica nos sites do portal CAPES e Scielo dos últimos cinco anos, artigos, livros da abordagem da psicologia analítica. Em síntese, ficou reiterado que há contribuição das artes no processo da Psicologia Analítica, pois tanto a Parábola do Filho Pródigo quanto a pintura de Rembrandt ilustram a codificação simbólica no processo de individuação do homem. Desse modo, compreendeu-se que o ser humano é um conjunto em transição contínua, em processo de aprimoramento incessante sob todos os aspectos considerados (filosóficos, sociológicos, espirituais, éticos, morais). Assim, nesse processo ininterrupto de transformação, surgem complexidades nas quais alguns conflitos desaparecem e outros permanecem na sua história antropológica, ancestral, como perspectivas de apreensão, conquistas que devem ser logradas.
\end{abstract}

Palavras-chave: O filho pródigo. Rembrandt. Psicologia Analítica. Complexo paterno.

\footnotetext{
${ }^{1}$ Artigo é resultante de Trabalho de Conclusão de Curso de Pós-graduação lato sensu pela Universidade Internacional da Paz Goiás (Unipaz-GO), Goiânia, Goiás, Brasil, e Pontifícia Universidade Católica de Goiás (PUC-GO), Goiás, Brasil. E-mail: lila-ramos@uol.com.br

${ }^{2}$ Doutorado em Psicologia pela PUC-GO, Goiás, Brasil. Pesquisadora em Saúde Mental e Clínica Psicodinâmica do Trabalho e Psicologia Analítica. Servidora Técnica Federal na Universidade Federal de Goiás (UFG-GO), Goiás, Brasil.

${ }^{3}$ Doutorado em Ciências da Religião pela Universidade Metodista de São Paulo, São Paulo, Brasil. Coordenadora do Curso de Pós-graduação em Arteterapia da Faculdade Censupeg-RJ, Rio de Janeiro, Brasil. Coordenadora do Curso de Pós-graduação em Psicologia Analítica da Unipaz-GO, Goiânia, Goiás, Brasil.
} 


\begin{abstract}
This study aims to identify some basic concepts of Analytical Psychology in Rembrandt's painting entitled "The Return of the Prodigal Son", inspired by the parable "The Prodigal Son", taken from the Bible, Luke's Gospel, chapter XV, verses 1-32. The precepts of Analytical Psychology on individuation, conscious, unconscious personal, collective, anima, animus, self, persona, symbols, complexes, paternal complex, individuation process, archetypes and their correlation with religious artistic expression were considered. The methodology was a bibliographic review on the websites of the CAPES and Scielo portal of the last five years, articles, books of the Jungian approach. In summary, it has been reiterated that there is contribution of the arts in the process of Analytical Psychology, since both the Parable of the Prodigal Son and the painting of Rembrandt illustrate the symbolic codification in the process of individuation of man. In this way, it was understood that the human being is a set-in continuous transition, in process of incessant improvement in all aspects considered (philosophical, sociological, spiritual, ethical, moral). Thus, in this uninterrupted process of transformation, complexities arise in which some conflicts disappear and others remain in their anthropological, ancestral history as perspectives of apprehension, achievements that must be achieved.
\end{abstract}

Keywords: Prodigal son. Rembrandt. Analytical Psychology. Paternal Complex.

\section{Introdução}

O ser humano é organizado, em sua forma física e psíquica, de maneira ímpar, que transcende uma análise superficial, a qual exige aprofundamento nos seus elementos constitutivos. Desse modo, Plotino, nascido em Licópolis, no Egito, filósofo pai da doutrina neoplatônica, discípulo de Amônio Sacas, elucidou com sabedoria, segundo os preceitos de Enéas, volume VI, o conhecimento de que o Uno não vem por meio da ciência e do pensamento, mas por meio de uma presença imediata, superior à ciência (HUISMAN, 2001).

Silva Júnior (2009) e Silveira (2003) contextualizam que Jung, médico psiquiatra, psicoterapeuta e fundador da Psicologia Analítica, teve uma família com veia religiosa bastante forte. Seu pai era pastor da Igreja Luterana, fato que explica seu interesse precoce pela filosofia e pela religiosidade. Jung foi um psiquiatra revolucionário ao valorizar a subjetividade, a fala e as histórias de seus pacientes. Dessa forma, a maioria de seus estudos surgiu de suas próprias experiências, evidenciadas em seu livro Memórias, sonhos e reflexões (2006), o qual remete ao conceito proposto por Plotino, visto que Jung foi um grande estudioso de filosofia.
Assim, ele traz para a humanidade inapreciável contribuição de suas reflexões, observações e práticas no estudo da transcendência do ser, da sua origem, da sua constituição de ser humano, do seu destino. Estudou várias culturas. Pesquisou muitas religiões (culturas religiosas) e doutrinas orientais, especialmente as mandalas no Budismo, para identificar o ser real, compreender o Complexo, o self. Portanto, Jung confirma o preceito de Plotino (STEIN, 2016).

Outrossim, o objetivo essencial da existência humana do ponto de vista psicológico na visão junguiana é facultar ao indivíduo a aquisição da sua totalidade, o estado de integralidade que age entre dois diferentes estados da sua constituição psicológica (JUNG, 2008a). Logo, compreendese que estado de integralidade são características arrebatadoras e místicas relativas a anima/animus, à personalidade humana, aos aspectos arquetípicos da sombra devido à sua natureza numinosa. Jung afirma, portanto, que "cada vez que um arquétipo aparece em sonho, na fantasia ou na vida, ele traz consigo uma influência específica ou uma força que the confere um efeito numinoso e fascinante ou que impele à ação." (JUNG, 2008a, p. 61-62).

Esse poder integral e irresistível dos arquétipos pode levar ao que Jung (2008b, §871) 
chama de participação mística, assim definida pelo autor: "consiste em que o sujeito não consegue distinguir-se claramente do objeto, mas com ele está ligado por relação direta que poderíamos chamar identidade parcial". Esse fenômeno está diretamente relacionado com as camadas mais arcaicas de nossa psique.

Trata-se do momento em que o indivíduo faz seu religare com o mítico, sente-se transcendente da Terra, ligado ao Deus que está dentro dele, que habita dentro de si, que vive inteiro dentro de cada célula do corpo, da alma. Em alguns momentos da vida, o homem sente-se partícipe desse processo numinoso.

Assim, cabe aqui trazer alguns aspectos para melhor entendimento do presente texto. Jung (2007) considera que o termo 'religião' designa a atitude peculiar a uma consciência alterada pela experiência do numinoso. Ele esclarece que, ao empregar o termo, não está se referindo a um credo, pois para ele a religião é uma função profundamente gravada na psique, e os seres humanos possuem a propriedade de formular imagens de Deus.

O contexto familiar de Jung, por ser religioso e acadêmico, contribuiu para suas experiências religiosas, centrais para o trabalho de toda a sua vida. Sua constante e duradora preocupação com a dimensão religiosa e com o sofrimento mental da humanidade o levou a tentar compreender os efeitos psicológicos da prática religiosa, a questão do bem e do mal. Nos últimos anos de sua vida, escreveu extensivamente sobre a dinâmica religioso-psicológica da vida humana. O Livro Vermelho, seu diário privado, retrata, simbólica e profeticamente, sua luta para superar a alienação espiritual, ocorrida devido ao nascimento de uma nova imagem de Deus em sua alma. Tratase de sua relação com a experiência numinosa e religiosa (SILVEIRA, 2003).

Desse modo, pode-se considerar que o mysterium tremendum et fascinans de Otto (2007) leva ao processo numinoso. Ele compreende que a experiência do elemento religioso é chamada de numinoso, presente em todas as religiões.
A experiência do numinoso na vivência daquele que faz ou gera a experiência, o sentimento de criatura é, ao mesmo tempo, sentimento de dependência. Assim, o sentimento da criatura é um reflexo da experiência do numinoso, o qual se apresenta como mysterium tremendus et fascinans (OTTO, 2007, p. 37-43).

O mysterium (mistério) pode ser entendido como o oculto, não evidente, não entendido, não cotidiano, não familiar. $\mathrm{O}$ mistério, enquanto tremendum (temor), se apresenta como espantoso, como se o sujeito fosse psicologicamente atingido por um milagre (mirum). Esse estado de espanto é produzido unicamente pelo numinoso, enquanto o mysterium (mais amplo) pode ser criado por uma série de outras experiências religiosas. $\mathrm{O}$ mistério religioso (mirum) se apresenta como totalmente outro. O numinoso experienciado é inapreensível em sua plenitude, de modo que não só as limitações do sujeito se interpõem entre ele e o mirum, mas a natureza e a incomensurabilidade do totalmente diferente são determinantes nesse processo.

Otto (2007) defende que não foi o simples medo do mundo que fez nascer a religião. $\mathrm{O}$ temor (tremendum) é causado pela ira, concebida como o próprio tremendum, entendido e expresso mediante a associação com algo natural da psique humana. O temor é algo que imprime ao numinoso o caráter distanciador, causando o receio e perturbando o sujeito da experiência religiosa.

Se, por um lado, a experiência do numinoso traz um aspecto distanciador, propiciado pelo tremendum, por outro, se apresenta comofascinans (atraente). $\mathrm{O}$ aspecto fascinante (fascinans) do numinoso é esquematizado pelos conceitos de amor, misericórdia, compaixão, caridade, revelando-se também nas exageradas exaltações do bem da salvação, as quais aparecem em quase todas as religiões. Assim, Otto (2007), partindo da compreensão da experiência do numinoso como mysterium tremendum et fascinans, faz perceber que a experiência religiosa não pertence especificamente à esfera do racional, mas do irracional. Este deve ser compreendido como 
misterioso e obscuro a ponto de não poder ser submetido ao pensar conceitual, mas acessível apenas ao sentir.

Ao voltar-se para as obras de Jung e para o que ele diz sobre o numinoso, descobre-se uma ênfase diferente daquela de Otto. Percebe-se que Otto tende a enfatizar a qualidade transcendente do numinoso, enquanto Jung enfatiza sua imanência. Para ele, a própria natureza da patologia assume uma qualidade numinosa, pois isso fica claro em sua declaração de que os deuses se tornaram doenças. Óbvias são, também, as diferenças significativas entre Otto e Jung. Jung reconheceu a importância da qualidade da cura do numinoso e acreditou que sua psicologia oferecia um bom terreno para experimentá-lo em um indivíduo, em vez de em um recipiente coletivo. Para Otto, a experiência numinosa confirma a religião coletiva, particularmente sua forma luterana de Cristianismo. Para Jung, seus encontros pessoais com o numinoso (tanto transpessoais quanto traumáticos) e os de seus analisados foram o começo da cura pessoal, sinais do processo de individuação, para além das restrições do coletivo (MIRANDA, 2018).

A Parábola do Filho Pródigo remete a todo esse contexto exposto, pois há várias operações alquímicas que tratam da jornada do herói, em que há um profundo arrependimento do filho por ter saído de casa, pego a herança e a gastado toda para após ver-se desamparado no mundo. Desse modo, resolve pedir perdão a partir do momento em que estabelece um religare com o Deus Pai, o Criador da Terra, que ama incondicionalmente, e decide voltar para a casa de seu pai biológico.

Permeado pelo contexto exposto, este estudo nasceu de uma inquietação pessoal sobre a problemática da relação irmãos e pais no contexto da Parábola do Filho Pródigo, bem como da tela "A volta do filho pródigo", de Rembrandt. Tem por objetivo geral uma breve análise da parábola "O filho pródigo", retirada da Bíblia Evangelho de Lucas, capítulo $\mathrm{XV}$, versículos 1-32 -, e da tela de Rembrandt, intitulada "A volta do filho pródigo". O objetivo específico é encontrar os preceitos da Psicologia Analítica na arte de Rembrandt, inspirada na parábola "O filho pródigo", retirada da Bíblia - Evangelho de Lucas, capítulo XV, versículos 1-32. Destarte, para melhor compreensão do estudo, descrevemse alguns desses conceitos básicos da Psicologia Analítica no próximo item, identificados na obra de Rembrandt sob análise.

\section{Método}

O método usado é a revisão bibliográfica e o qualitativo. Segundo Minayo (2010, p. 57), o método qualitativo pode ser definido como " [...] o que se aplica ao estudo da história, das relações, das representações, das crenças, das percepções e das opiniões, produtos das interpretações que os humanos fazem a respeito de como vivem, constroem seus artefatos e a si mesmos, sentem e pensam".

Penna (2003) considera que a pesquisa qualitativa é a mais adequada às ciências humanas e sociais, pois buscam a compreensão dos fenômenos humanos por meio da interpretação. Considera ainda que nela se desenvolve uma produção teórica que circunda a construção permanente de modelos de inteligibilidade que lhe deem consistência a um campo ou um problema na construção de um conhecimento. Assim, buscaram-se os conceitos básicos em Jung, obedecendo ao critério cronológico para que se pudesse observar com clareza o desenvolvimento daqueles. Em seguida, fez-se, no portal da CAPES e no site Scielo, a revisão de artigos que discorressem sobre os conceitos básicos de Jung, principalmente nos últimos cinco anos. Foram encontrados os seguintes autores: Gewehr (2019); Peres, Barros, Zanella (2019); Xavier (2016); Penna (2015); Batista (2014). Ilustrou-se também o artigo com a tela de Rembrandt, intitulada "A volta do filho pródigo", que permeou a análise da parábola. Exposto o método, passa-se à conceituação de algumas premissas junguianas. 


\section{Alguns Conceitos Básicos da Psicologia Analítica}

Segundo Duarte (2017), a trajetória científica de Jung foi marcada pelo romantismo de Goethe, por sua contemplação intensa do meio natural e pelo profundo respeito que ele mantinha pela natureza e sua conexão com ela. Jung utilizou em sua teoria inúmeras observações da natureza para fundamentar tendências do psiquismo humano, por compreender que o homem tem necessidade de reencontrar-se com a originalidade primária de seu próprio ser. "Se tivermos a natureza como guia, nunca trilharemos caminhos errados." (JUNG, 2001, §34).

Silveira (2003) afirma que Jung representa a psique como um vasto oceano (inconsciente), do qual emerge uma ilha (consciente). Para qualquer conteúdo psíquico tornar-se consciente, ele terá de se relacionar com o ego e, segundo a autora, o ego para Jung é um complexo de elementos numerosos, formando uma unidade coesa, capaz de transmitir a impressão de continuidade e de identidade consigo mesma. Dessa maneira, Jung usa com frequência a expressão 'complexo do ego', em vez de simplesmente "ego" (WHITMONT, 1995).

Sobre o inconsciente, ele explica que se trata da "[...] natureza que nunca se engana" (JUNG, 2011d, §95) e o classifica em pessoal e coletivo.

Pode-se compreender o inconsciente pessoal em Jung como aquele que se refere às camadas mais superficiais do inconsciente, cujos limites com o consciente são bastante imprecisos. Estão incluídas aí as percepções, impressões subliminares dotadas de carga insuficiente para atingir o consciente como, por exemplo, as recordações penosas de serem relembradas. Os conteúdos do inconsciente pessoal são os complexos de tonalidade emocional, que constituem a intimidade pessoal da vida anímica.

Já o inconsciente coletivo é a camada mais profunda do inconsciente. É a expressão psíquica da identidade humana, independentemente de todas as diferenças raciais e sociais. Trata-se de natureza universal, pois são conteúdos idênticos em todos os seres humanos; um substrato psíquico comum de natureza psíquica, suprapessoal, que existe em cada indivíduo.

Os conteúdos do inconsciente coletivo são os arquétipos que ressaltam a capacidade dinâmica do inconsciente de criar imagens. Arquétipo, portanto, é uma espécie de aptidão para reproduzir constantemente mítica e semelhante. São forças ou tendências à repetição das mesmas experiências. Quando um arquétipo aparece em sonho, na fantasia ou na vida, ele traz consigo uma força, uma influência que the confere um efeito numinoso que impele uma ação (JUNG, 1999). Os arquétipos são, assim, conteúdos psíquicos arcaicos herdados dos ancestrais, vivências repetidas desses, a evolução genética da espécie humana. Por isso, o arquétipo pode ser considerado equivalente ao instinto, refletindo todos os sentidos, todos os padrões de comportamento da natureza humana (DUARTE, 2017).

$\mathrm{O}$ arquétipo tem em sua natureza a condição de polaridade. Assim, ele se apresenta com grandes ondas de força para ser percebido pela psique e atingir seu objetivo, propiciando a individuação. Com esse objetivo, o arquétipo fazse ser notado, vivido, sentido, conscientizado por meio das imagens dos sonhos, sintomas/doenças, sincronicidades de experiências do dia a dia, rituais religiosos, energia criativa da psique ou de criações artísticas, mitos, expressões idiomáticas (JUNG, 2003).

$\mathrm{O}$ arquétipo fraterno mostra a importância da estruturação das bases de relacionamento adulto, maduro, embora assim não se perceba. Como imagem arquetípica, o irmão faz parte da psique humana, mesmo sem sua vivência, por meio de um laço consanguíneo, uma vez que se busca a experiência da fraternidade com os irmãos escolhidos como amigos, parceiros (BARCELLOS, 2009).

Jung (2003) considera que o arquétipo paterno reflete a imagem do pai com seu universo próprio. $\mathrm{O}$ amor paterno "não sabe se sabe o que é". O amor de mãe é aqui e agora. O amor do pai é lá, então é uma perspectiva de futuro. 
Remete à proteção enquanto se direciona ao poder no sentido de trazer este para si e situarse na capacidade de comandar do(a) filho(a); ao estímulo ao desenvolvimento da razão; à vivência do mundo objetivo e prático de valores, regras, leis; ao encorajamento de distanciar o contato ao mundo da mãe, para desenvolver a objetividade; ao desenvolvimento do universo egóico, enfim, a um continente diferente. Se, por um lado, a relação pai versus filha é induzida a dar ênfase no encontro com um caminho de diferenciação ou universo estrangeiro, por outro, a relação pai versus filho volta-se a dar destaque ao mundo masculino. Desta forma, o pai aparece como imagem desconhecida e intuitiva no início da vida do/da filho/filha. Isto é, nos homens o complexo paterno positivo produz uma certa credulidade em relação a uma instância autoritária e uma prontidão a submeter-se diante de todas as normas, valores espirituais. Nas mulheres, dá origem a vivas aspirações e interesses espirituais.

Jung (2006, 2008a) designa por complexo afetivo um grupamento de representações mentais mantidas juntas por emoção. Os complexos se organizam a partir de experiências emocionais significativas do indivíduo. O próprio ego - o centro da consciência, para Jung - seria um complexo, o complexo egóico. Outros complexos na personalidade podem agir sobre o ego, interferindo no funcionamento adequado da consciência, perturbando a adaptação criativa do sujeito.

Assim, cabe aqui discorrer sobre o complexo paterno, pois possibilita ampliar o olhar da obra de Rembrandt nesse contexto. Na mitologia grega, os deuses patriarcais - Urano, Cronos, Poseidon, Hades e Zeus - são homens autoritários que vivem no céu ou no alto das montanhas, governam do alto e à distância. Apesar de todo poder, sentem medo de serem destronados pelos próprios filhos. A figura paterna na visão mitológica grega colabora para a formação do complexo paterno. As imagens de pai vinculadas a Urano, Cronos, Hades e Poseidon são confrontadas com a imagem de pai mais próxima do ideal, representada por Zeus, como pai pessoal. Este confronto será presente na vida do sujeito como filho, especialmente na infância, colaborando para a ampliação do complexo paterno do indivíduo (TOMMASI; SOARES, 2015).

O mito de Cronos é um exemplo que reflete as formas de vivenciar o complexo paterno, inclusive na parábola referida. Ele traz em sua origem Urano, seu pai, que não reconhece os filhos. Segundo a narrativa conhecida, Cronos devorava seus filhos assim que nasciam, com medo de ser deposto por um dos descendentes. Réia, sua irmã e esposa, contudo, protege o filho Zeus e o entrega aos cuidados de Quíron e da cabra Amaltea (considerada uma das versões do próprio Cronos). Assim, é como se o lado luminoso do Pai (Amaltea) protegesse o filho do lado devorador e sombrio. Há uma ação de proteção, apesar de devorá-los, ação que ceifa, que cerceia, mas que também estrutura, dá os limites necessários. É a ambivalência do arquétipo nas relações com o pai, que também constitui o complexo paterno (TOMMASI; SOARES, 2015).

Ademais, Cronos pode ser constelado como o complexo paterno negativo no aspecto do pai rígido, que mais cerceia, critica e recrimina do que cuida e nutre, propriamente, como se poderia identificar em Zeus. Presos nesse aspecto sombrio, as pessoas que apresentam esse quadro carecem dos aspectos luminosos do puer, da força criativa, da alegria, da leveza, da flexibilidade necessária para colher as diversas manifestações da vida (ALVARENGA, 2007).

Háuma comparação da mitologia apresentada como um processo no tempo que age, opera, realiza, entendendo a função fraternal como um termo utilizado para indicar atividades de educação nos tempos atuais. Isso sugere uma reflexão na qual há uma perspectiva familiar hierárquica ou vertical da relação pais-filhos. Aos poucos, percebe-se que, a partir de uma perspectiva arquetípica, aparece a sombra, projeção da vida não vivida, que explica a discórdia fraternal presente na origem mitológica de tantas civilizações (BARCELLOS, 2009).

Destarte, Zeus cresce, fortalece-se e castra Cronos. Então, esse ciclo de castração/tomada de poder simboliza a esfera da renovação temporal, 
cíclica do poder social masculino. Está presente na mitologia da maturação, evitando a perpetuação do puer na psique, a qual poderia cristalizar o narcisismo, o egocentrismo. Há a necessidade de aceitar o processo dos limites para a fantasia de onipotência pueril, para a estruturação saudável do ego. Ademais, no complexo paterno, tem-se que, na relação pessoal entre pai e filho, a psique escolhe lidar com essas forças de forma mais ou menos criativa, equilibrada, com quadros de fixações estereotipadas, sombrias. O complexo paterno pode se constelar sob a ação de Cronos, trazendo um mundo interior repleto de regras, leis e limites rígidos que afastam o ser humano da relação, das vivências sensoriais nutridas pela vida (JUNG, 1981).

Simplificando, Jung (2003) designa por complexo paterno/materno um grupo de associações inconscientes ou impulsos inconscientes fortes que se referem especificamente à imagem ou arquétipo do pai/mãe. Tem sempre por centro uma experiência afetiva suficientemente forte para constituir um núcleo que se tornará um ímã diante das experiências com as mesmas cores afetivas. As experiências da mãe e do pai são suficientemente fortes para acionar a criação desses complexos. O complexo é uma interiorização da relação que tivemos com uma pessoa e as ferramentas mais comuns para tornar os complexos paternos conscientes são: os sonhos com suas figuras paternas, sintomas ligados à força e ao logo; repetições de situações corriqueiras que envolvam figuras paternas; e ligação com a vida social de forma desarmônica ou dependência ou independência excessiva. Consequentemente, o complexo paterno em relação ao filho limitará a formulação da sua persona e influenciará a formação da sua sombra. O complexo paterno refletirá na sua forma como este homem-filho expõe-se externamente e no social. Em relação à filha, o complexo do pai influenciará o seu desenvolvimento do animus e projeção da anima do pai sobre a filha. Consequentemente, o complexo paterno provocará interferências na relação desta mulher-filha com seus parceiros.
O símbolo, segundo Jung (2008b), é uma forma de significado extremamente complexa, além de não ser unicamente racional: transita entre o consciente e o inconsciente; se é, de uma parte, acessível à razão, de outra, esta lhe escapa para fazer vibrarem cordas ocultas no inconsciente.

Silveira (2003, p. 71) afirma que para Jung "um símbolo não traz explicações; impulsiona para além de si mesmo na direção de um sentido ainda distante, inapreensível, obscuramente pressentido e que nenhuma palavra de língua falada poderia exprimir de maneira satisfatória". É, então, a expressão de coisas significativas para as quais não há, no momento, formulação mais perfeita. Por fim, ainda segundo Jung (2008b), é uma linguagem universal capaz de exprimir por meio de imagens fatos que transcendem as problemáticas específicas dos indivíduos.

A conceituação de persona, por sua vez, é compreendida por Jung como uma função natural, destinada à adaptação social do indivíduo: “[a] persona é um complicado sistema de relação entre a consciência individual e a sociedade; é uma espécie de máscara destinada, por um lado, a produzir um determinado efeito sobre o outro lado, a ocultar a verdadeira natureza do indivíduo." (JUNG, 2011c, §305).

O símbolo da persona é, então, a máscara, que está vinculada ao termo "personagem". Por meio da persona, os seres humanos desempenham funções/papéis sociais em seus grupos.

Outro aspecto importante é o de sombra:

O inconsciente pessoal contém lembranças perdidas, reprimidas (propositalmente esquecidas), evocações dolorosas, percepções que, por assim dizer, não ultrapassaram o limiar da consciência (subliminais), isto é, percepções dos sentidos que por falta de intensidade não atingiram a consciência e conteúdos que ainda não amadureceram para a consciência (JUNG, 1999, §103).

Assim, a sombra é uma espessa massa de componentes diversos, aglomerando pequenas fraquezas, aspectos imaturos ou inferiores, complexos reprimidos, mas na sombra poderão 
ser discernidos traços positivos, qualidades valiosas que não se desenvolveram devido a condições externas desfavoráveis (SILVEIRA, 2003). Alvarenga (2007, p. 90) complementa, associando o mito de Medusa para apresentar o complexo da sombra:

Medusa representa o medo absoluto, advindo da visão epifânica da sombra; o terror diante de nossas próprias monstruosidades, refletidas no espelho do olhar da deusa. Novamente surge a pedra, mas a pedra produzida por Medusa é a pedra da imobilidade, estéril, ressecante, mortal. Desta vez, Poseidon tem a função de destruir a muralha e inseminar vida no corpo/ pedra da divina. A crina preta, na qualidade de divindade das virtualidades, fertilizador continente da indiferenciação, mistério e emoções, busca Medusa na tentativa de integrar aspectos clamantes por atualização. É o vir-aser penetrando na sombra paralisante. Os frutos desse encontro precisam do herói para vir à luz. Esse mitologema fala de um caminho de estruturação de consciência, via enfrentamento e integração simbólicos de aspectos da sombra.

Entende-se que a sombra é a parte não vivida da personalidade humana; por isso, seu dinamismo pode conter tanto o bem como o mal. Essa parte não vivida é inconsciente ao ser, inquietante, a qual se manifesta de forma extrema, primitiva, desajeitada, mas nela existe potencial positivo para novos dons e talentos. Entretanto, sempre que se trata dela como arquétipo defronta-se com as mesmas dificuldades constatadas em relação ao animus e anima (JUNG, 2011b).

Importa, nessa esteira, registrar os conceitos da anima e do animus. Jung (2011d) afirma que a anima é composta das experiências do homem em relação ao ente feminino, um aglomerado hereditário inconsciente de origem antiga. É a representação psíquica das experiências com o feminino presente no corpo masculino. É um resíduo de todas as impressões fornecidas pela mulher. A anima encerra os atributos fascinantes do feminino; apresenta-se personificada nos sonhos, nos contos de fadas, no folclore de todos os povos, nos mitos, nas produções artísticas. Trata-se do arquétipo feminino.
Em seguida, Jung (2011b) conceitua animus à masculinidade existente no psiquismo da mulher. A masculinidade é inconsciente, manifesta-se como intelectualidade. $\mathrm{O}$ animus opõe-se à própria essência feminina, condensa as experiências que a mulher viveu nos seus encontros com a figura masculina no curso dos milênios, vivenciada pelo homem no decorrer dos séculos. É a partir desse material inconsciente que se modela a imagem do homem que a mulher possa projetar nos homens reais. A sua personificação está na figura masculina presente em sonhos, contos de fada, mitos, heróis, feiticeiros, criminosos, homens brutos, homens requintados.

Já o conceito de Self abarca não somente a psique consciente, como também a inconsciente, sendo, portanto, uma personalidade que também somos. É impossível chegar a uma consciência aproximada de si mesmo, porque por mais que se amplie o campo da consciência, sempre haverá uma quantidade indeterminada e indeterminável de material inconsciente que pertence à totalidade de si mesmo. Assim, Self é o centro da personalidade total, como o ego é o centro do campo consciente. Esse é o motivo pelo qual o "si mesmo" sempre constituirá uma grandeza que nos ultrapassa (JUNG, 2011d).

$$
\text { Cavalcante (1992) conceitua que }
$$
enantiodromia é um termo extraído da filosofia de Heráclito, significando que quando algo está fortemente identificado, tende a cair em seu oposto, como um pêndulo. Esse conceito foi reformulado por Jung (2013) para ser aplicado ao funcionamento dos processos energéticos da mente humana quando há um conflito entre os interesses da mente consciente e inconsciente. A psique, por meio da enantiodromia, mostra que alguns aspectos da vida estão sendo excessivamente desenvolvidos ou valorizados, enquanto outros, de igual importância, estão sendo desprezados ou ignorados. Esse movimento tanto pode ocorrer no âmbito da psique coletiva quanto da individual.

Para Jung (2008a), os símbolos são representações dos conflitos que se estabelecem 
e apontam para a possibilidade de compreensão deste conflito. Chevalier e Gheerbrant (1996) ajudam a entender o pressuposto de Jung, para quem a imaginação simbólica e seu dinamismo são possibilidades de uma diferenciação, bem como de desenvolvimento da consciência pela integração dos opostos em direção a uma totalidade. Uma integração com o mundo que já existia no início do desenvolvimento do psiquismo individual, no contato vital com o inconsciente.

Por fim, conceituar o processo de individuação é tratar do eixo da Psicologia Analítica. Em Stein (2016), concebe-se que a individuação é um arquétipo, e o processo de individuação toma em atenta consideração os componentes coletivos da psique humana (conteúdos do inconsciente coletivo), permitindo esperar uma melhor integridade do indivíduo com ele mesmo. Consiste em confrontar os vários aspectos sombrios, reconhecendo-os, não se despindo da persona e das imagens primordiais:

A individuação, em geral, é o processo de formação e particularização do ser individual e, em especial, é o desenvolvimento do indivíduo psicológico como ser distinto do conjunto, da psicologia coletiva. É, portanto, um processo de diferenciação que objetiva o desenvolvimento da personalidade individual. Também, o processo de individuação não leva ao isolamento, mas a um relacionamento coletivo mais intenso e mais abrangente. (JUNG, 2008b, §853).

Então, o processo de individuação não se dá em um desenvolvimento linear, mas em um movimento de circunvolução que conduz a um novo centro psíquico, o qual Jung (2008b) denominou de Self (si mesmo). Quando consciente e inconsciente vêm a ordenar-se em torno do Self, a personalidade se completa.

Desse modo, passa-se a uma breve análise da parábola de Jesus "A volta do filho pródigo" (BÍBLIA, 2018), representada na imagem da tela de Rembrandt. A partir dessa imagem e dos conceitos da Psicologia Analítica expostos, estabelece-se a análise.

\section{Parábola "O Filho Pródigo"}

[...] E Jesus continuou. 'Um homem tinha dois filhos. O filho mais novo disse ao pai: 'Pai, dá-me a parte da herança que me cabe'. E o pai dividiu os bens entre eles. Poucos dias depois, o filho mais novo juntou o que era seu e partiu para um lugar distante. E ali esbanjou tudo numa vida desenfreada. Quando tinha esbanjado tudo o que possuía, chegou uma grande fome àquela região, e ele começou a passar necessidade. Então, foi pedir trabalho a um homem do lugar, que o mandou para seu sítio cuidar dos porcos. Ele queria matar a fome com a comida que os porcos comiam, mas nem isto lhe davam. Então caiu em si e disse: Quantos empregados do meu pai têm pão com fartura, e eu aqui, morrendo de fome. Vou voltar para o meu pai e dizer-lhe: 'Pai, pequei contra Deus e contra ti; já não mereço ser chamado de teu filho. Trata-me como um dos teus empregados'. Então ele partiu e voltou para seu pai. Quando ainda estava longe, seu pai o avistou e foi tomado de compaixão. Correu-lhe ao encontrou, abraçou-o e o cobriu de beijos. O filho, então, lhe disse: 'Pai, pequei com Deus e contra ti. Já não mereço ser chamado teu filho'. Mas o pai disse aos empregados: 'Trazei depressa a melhor túnica para vestir meu filho. Colocai-lhe um anel no dedo e sandálias nos pés. Trazei um novilho gordo e matai-o, para comermos e festejarmos. Pois este meu filho estava morto e tornou a viver; estava perdido e foi encontrado'. E começaram a festa. O filho mais velho estava no campo. Ao voltar, já perto de casa, ouviu música e barulho de dança. Então chamou um dos criados e perguntou o que estava acontecendo. Ele respondeu: 'É teu irmão que voltou. Teu pai matou o novilho gordo, porque recuperou o filho são e salvo'. Mas ele ficou com raiva e não queria entrar. $\mathrm{O}$ pai, saindo, insistiu com ele. Ele, porém, respondeu ao pai: 'Eu trabalho para ti há tantos anos, jamais desobedeci a qualquer ordem tua. E nunca me destes um cabrito para festejar com meus amigos. Mas quando chegou este teu filho, que esbanjou teus bens com prostitutas, matas para ele o novilho gordo'. Então o pai lhe disse: 'Filho, tu estás sempre comigo, e tudo que é meu é teu. Mas era preciso festejar e alegrarnos, porque este teu irmão estava morto $\mathrm{e}$ tornou a viver, estava perdido e foi encontrado (BÍBLIA, 2018). 
O excerto inicia-se do seguinte modo: "Um homem tinha dois filhos" (Lc 15: 11-32). O filho mais novo resolve pedir ao pai sua parte da herança e vai para uma terra distante viver sua vida como achava que deveria viver. Nessa terra, gasta cada centavo com prazeres, até que todo o seu dinheiro acaba e ele se torna praticamente um mendigo. No momento mais crítico, sente atração até pela lavagem que era dada aos porcos, tamanha era a fome que sentia. Nesse momento, lembrase da casa do pai e, arrependido, resolve voltar. É recebido com muita festa pelo pai e rejeitado pelo irmão mais velho (BÍBLIA, 2018).

A tela "A volta do filho pródigo" foi produzida no ano de 1662. Inspirado pela Parábola, Rembrandt entrega-se aos pincéis com paixão.

Figura 1 - The return of the prodigal son.

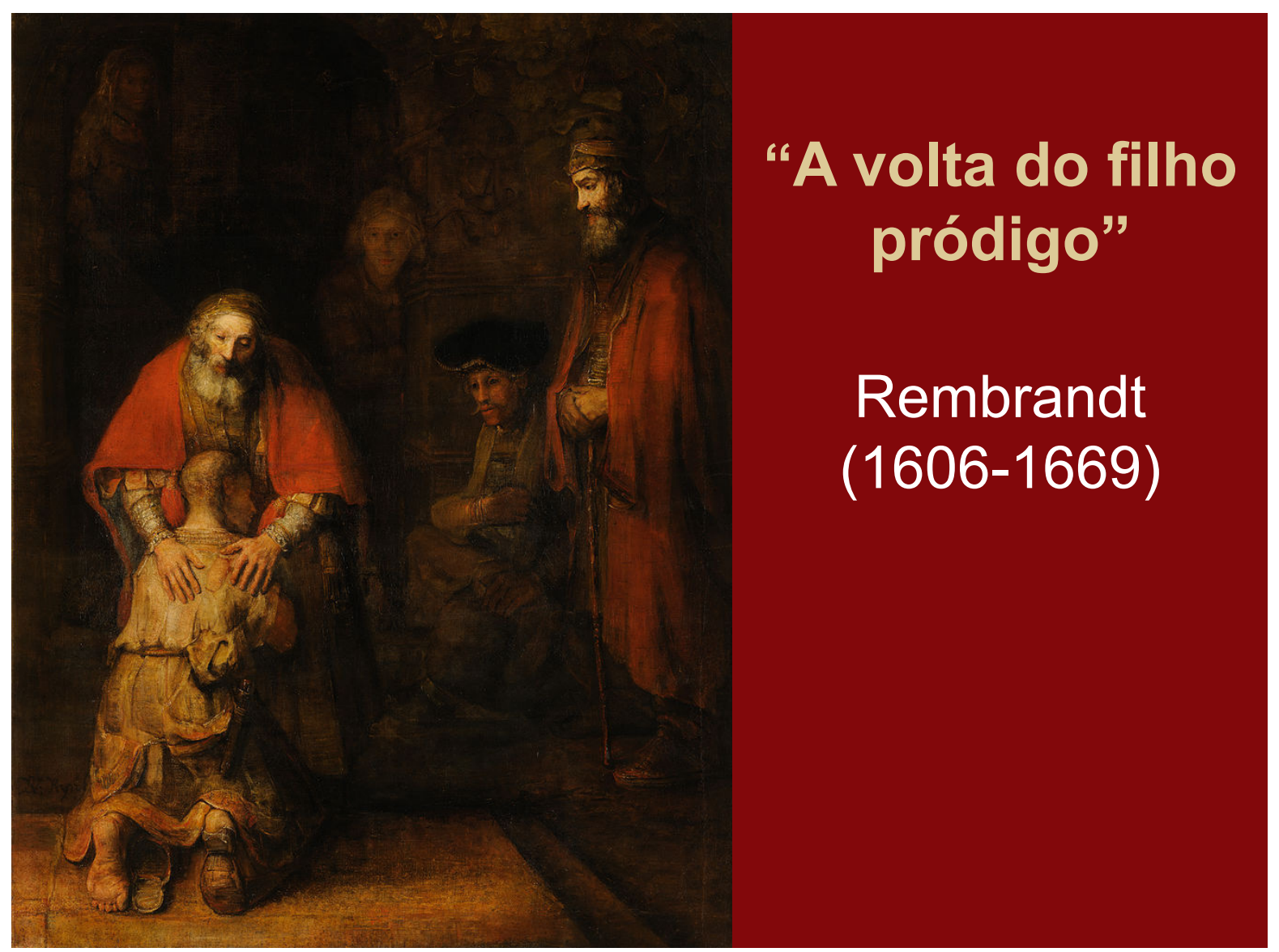

(C. 1662, Óleo sobre tela, $262 \mathrm{~cm}$ x $206 \mathrm{~cm}$. Museu Hermitage, São Petersburgo, Rússia).

Fonte: Rembrandt (1662)

\section{Resumo da Biografia de Rembrandt}

Rembrandt Harmenszoon van Rijn foi considerado um dos maiores pintores do claroescuro. Ele conseguia arrancar da treva a realidade dos seus desenhos. Quando já velho, dedicou-se a pintar particularmente idosos e cegos, pois também foi perdendo a visão. A história de Rembrandt é uma história notável da psicologia humana, da busca da verdade. Nascido no ano de 1606, em Leyden, uma cidade da Holanda, por volta de 1634 casou-se com sua sobrinha Saskia, uma jovem bela e rica, a quem muito amou.

O pintor e sua primeira esposa tiveram quatro filhos, três deles falecidos logo após o nascimento. $\mathrm{O}$ quarto filho, de nome Titus, foi o único a chegar à maioridade, vindo a falecer aos 27 anos de idade, um ano antes da morte do pai. 
Uma quinta filha de Rembrandt foi concebida com outra mulher, Hendrickje Stoffels, sua terceira companheira, com quem veio a viver anos após o falecimento de sua esposa (SLIVE, 1995, p. 82).

Rembrandt era muito narcisista. Em seus autorretratos iniciais, estava sempre vestido com roupas de veludo, com chapéus de pluma, como os homens mais fanfarrões de Amsterdã.

Amealhou uma grande fortuna, mas em virtude das imensas dívidas acumuladas para sustentar a vida faustosa que levava e da hipoteca para a aquisição de sua propriedade, entrou em total ruína financeira (BULL et al., 2006, p. 28).

Os biógrafos discordam muito quanto a fatos específicos, mas afirmam que o caráter de Rembrandt não era dos melhores e que ele teria internado a segunda companheira, Geertje Dircks, ama de seu filho Titus, em um hospício, sob a alegação de que ela estaria acometida de alucinações mentais, após processá-lo por quebra de promessa, tudo para poder ver-se livre e, assim, prestar atenção em si mesmo. Após, viveu maritalmente com Hendrickje Stoffels, já citada, com quem teve sua quinta filha, nascida em 1654 (SLIVE, 1995, p. 82).

Sua companheira e seu filho Titus abriram uma empresa para a venda e administração de suas obras, contratando o mestre pintor como empregado a fim de protegê-lo dos credores e de si mesmo ${ }^{4}$. Nesse período, ele já havia malbaratado toda sua fortuna e bens, que foram levados a leilão duas vezes. Foi reduzido à miséria mais extrema, indo residir em um bairro miserável de Amsterdã, onde produziu telas incomparáveis, como "A descida da cruz", de vigor incomum, na qual, no meio da sombra, ele coloca o corpo de Jesus em luz, em estado luminoso. Além disso, é o primeiro pintor que tira Jesus da cruz sem a coroa: um Jesus totalmente livre, sem ego, que havia atingido a plenitude do Reino dos Céus ainda na terra (SVETLANA, 2010).
Sobre a trajetória e relevância artística de Rembrandt, sobreleva descrever brevemente as fases de sua obra, de maneira a contextualizar melhor este estudo. É sabido que, quando criança, já demonstrava interesse pelas artes plásticas, especificamente pela pintura. Ao tornar-se jovem, matriculou-se na universidade de sua terra natal e foi aprendiz do pintor holandês Jacob Swanenburgh. Logo, abriu seu próprio estúdio de arte em sua cidade.

Seu talento foi descoberto em 1629. Teve várias encomendas de pinturas para a corte de Hague. Entre 1630 e 1640, ficou muito conhecido no cenário artístico europeu e, em especial, no holandês. Grande parte de suas famosas obras foi realizada neste período (SVETLANA, 2010).

Desse modo, o estilo artístico de Rembrandt compreendeu:

- $\mathrm{Na}$ década de 1625/1630: temas religiosos e alegóricos. Nessa fase, o detalhismo fez-se muito presente em suas pinturas;

- Na primeira metade da década de 1630: temas mitológicos, cenas da Bíblia, paisagens naturais. Nessa época, suas obras foram marcadas pelo formato ampliado e contraste alto;

- Na década de 1640: tom mais sombrio nas suas pinturas. O formato reduziu de tamanho;

- Na década de 1650: estilo mais detalhado, fino. Com cores fortes, retratou personagens bíblicos de forma individual; e

- Nos últimos anos de sua vida: autorretratos (SVETLANA, 2010).

Morreu no dia 4 de outubro de 1669, sendo sepultado em campa rasa, desconhecendo-se ainda hoje a localização precisa (SVETLANA, 2010).

\footnotetext{
${ }^{4}$ O biógrafo de Rembrandt, Christoph Driessen (2012, p. 213), credita a notável produtividade do pintor, no início da década de 1660, a Hendrickje, que lhe prestava apoio fundamental na condução dos negócios. Ela praticamente tentou reorganizar a vida do mestre e impediu sua queda completa após sua falência.
} 
A trajetória de Rembrandt em muito lembra a do filho pródigo. Com efeito, a vida e a obra do pintor apresentam um homem que experimentou riqueza, pobreza, alegria, perdas e tristeza. Teve fama e fortuna. Esbanjou seus bens com um modo de vida cheio de excessos e egoísmo, o que o levou a um sofrimento profundo. O filho pródigo, como ele, perde o dinheiro herdado de seu pai e sua família. Deduz-se que a parábola possivelmente faz Rembrandt perceber-se como o jovem nela retratado, visto que o pintor vivenciou pessoalmente a experiência relatada em sua amplitude. Tal fato parece refletir na sua arte, especificamente, na tela "A volta do filho pródigo".

\section{Abordagem da Teoria Analítica na Tela de Rembrandt Sobre a Volta do Filho Pródigo}

A tela "A volta do filho pródigo" foi produzida no ano de 1662. Inspirado pela Parábola, Rembrandt entrega-se para apresentar através de sua arte a verdadeira volta para casa. Svetlana (2010) afirma que nas pinturas da idade madura Rembrandt trabalha a cor para atrair no homem o sentido do tato, mediante o sentido da visão. Ele a coloca na tela com o pincel e trabalha a sua densidade com a espátula e os dedos: parece até que se pode apoiar a mão nela, exatamente como o pai nas costas do filho.

Inicia-se aqui uma visão geral da tela. Jung (2006) estabelece que o estado numinoso faculta ao ser o perfeito equilíbrio dos polos opostos, ou seja, toda vez que ocorre no indivíduo uma rigidez, o polo oposto insurge-se, levando-o ao outro lado da questão. Significa dizer que o inconsciente se opõe ao ego. Um é consciente, vigilante; o outro é inconsciente, adormecido, que desperta, se acionado pelo oposto. Um se encontra na razão; o outro no sentido ou vice-versa. Percebe-se o processo na enantiodromia, que aponta para o mistério que nos organiza, nos constitui, nos confronta e nos conduz a nós mesmos com quem somos: é o sagrado, a busca pela unificação dos opostos.

No contexto junguiano, o estado psicológico depende da forma como se administra e se conduz o equilíbrio dos opostos: indivíduo e sociedade; masculino e feminino; consciente e inconsciente; ego e sombra; extroversão e introversão; sofrimento e alegria; amor e desejo de poder; matéria e psique; espírito e corpo; razão e emoção; entre tantos outros. Quando se assume uma atitude unilateral ou quando o curso da vida está seguindo uma única direção em termos de valores e interesses, pode acontecer de se constelarem, na consciência, os conteúdos que até então foram negligenciados. $\mathrm{O}$ inconsciente atua de modo compensatório em relação à consciência, complementando-a com conteúdos que favoreçam o equilíbrio. Esse movimento pode tornar-se responsável pela formação dos processos neuróticos e psicopatológicos, por sintomas psicossomáticos, gerando doenças como última tentativa de integração (JUNG, 2013).

No âmbito do contexto de uma cultura patriarcal, há uma valorização excessiva de todas as características associadas ao masculino - o Logos, a claridade, a razão, a consciência, a ordem, a objetividade, a lógica, a competitividade, a atividade, a força, a realidade física e material - em detrimento de tudo aquilo que esteja relacionado ao feminino - o Eros, o obscuro, a intuição, o caos, a flexibilidade, a cooperação, a passividade, a fraqueza, o instintivo e o criativo, e o mundo das emoções, dos mistérios, dos sonhos e do inconsciente. A hipertrofia e o desgaste da ordem patriarcal vigente surgem por enantiodromia (JUNG, 2003, 2013).

$\mathrm{Na}$ tela, a figura do pai com as mãos nas costas do filho pródigo apresenta um pai pater/ mater. Parece ser o símbolo de Deus pai, Deus mãe, gerador da vida, o fulcro gerador da vida, sem polaridade. As mãos são um símbolo muito importante: a esquerda é grosseira, pesada, cravada na pele do filho sobre a camisa rasgada. É o animus, a mão que trabalhou a terra, é a mão do arado. A mão direita, nas costas do filho, tem dedos longos, leves, não calejados, demonstrando ternura, suavidade: é a anima. Em contraste, a mão direita dos fariseus é escura, grande, cobre a mão esquerda macia - eles estavam condenando e não tinham compaixão (TOMMASI; SOARES, 2015). 
O conflito é percebido por meio das representações simbólicas culturais e pessoais, remetendo as primeiras às manifestações arquetípicas na consciência coletiva. É possível encontrar narrativas mítico-religiosas na iconografia religiosa (uma forma de linguagem visual que utiliza imagens, pinturas e outras para formalizar um tema religioso), cuja estrutura é similar nas mais diferentes culturas.

As representações simbólicas pessoais são os símbolos que correspondem à atualização do arquétipo pela projeção em situações ou imagens. Podem ser símbolos de cruz, santo, situações típicas que marcam a vida do ser humano, como o sair da casa dos pais, um rompimento ou uma perda afetiva. São situações que imprimem um significado para o indivíduo (JUNG, 2008a).

Percebe-se que o pai tem um olhar duro, um olhar masculino, que remete ao pensar na simbologia de quem sabia que o filho voltaria; que seu filho abandonou o lar por inexperiência em busca de algo diferente para sua vida. Observase um pé descalço, o outro calçado do filho que parecem simbolizar a experiência de sair de casa, a destruição do tempo e, ao mesmo tempo, o retorno. Além disso, os pés são alicerces, raízes.

Outra observação da imagem da tela é o rosto e a cabeça do filho, que está no cosmo, no coração, no estômago do pai. É a infância, o retorno para sua casa, para o arquétipo familiar, o complexo de pai/mãe. Ele representa, naquela posição, um feto, pois o arquétipo do pai, vivenciado pelo pai real, é o símbolo que promove a estruturação psíquica da criança e lhe permite abrir-se para o horizonte de novas possibilidades (CAVALCANTE, 1995). Percebe-se a sombra desenvolvendo um papel para equilibrar o ego e o Self, avançando para o estado numinoso (JUNG, 2008b). A parábola retrata a humanidade que, caindo no pecado no Éden por meio de Adão, retorna a Deus depois de caminhar, sem rumo, e é acolhida por Ele.

Quando se visualiza a tela, o fariseu, o irmão mais velho da parábola, está à direita do observador, em primeiro plano. Ele olha para o pai e para o filho pródigo com uma carranca de condenação. O coletor de impostos está sentado perto do centro. Ele bate no peito em humildade e confissão de sua necessidade de receber misericórdia do pai para com o filho pródigo. Homem ou mulher ao centro da tela. Ele ou ela está olhando com interesse, perto do braço do pai, mas parece muito distante. Figura sombria no canto superior esquerdo. Ele ou ela mostra-se distante, observando o pai amar o filho pródigo, mas não entra na experiência pessoalmente. Nesse contexto, vê-se que a arte separa e reúne.

Assim, pode-se remeter para a teoria analítica o seguinte: o jovem viajou para um país distante depois de solicitar a seu pai sua parte na herança, simbolizando o Self. Quando o filho tem um insight sobre a generosidade do pai, o seu ego desperto o faz retornar para a casa do progenitor. O Self uniu-se ao ego e trouxe, naquele momento, um estado numinoso de tranquilidade e inquietação, de incômodo e de bem-estar. O ego, então, está para o Self assim como a parte está para o todo. É alcançado através da união do consciente com os conteúdos inconscientes. Quando ocorre esse encontro entre o ego e essa imagem arquetípica, ele é integrado na psique. Seria a imagem interior, a Imago-Dei que cada um carrega em seu íntimo. Essa imago é capaz de produzir sentimentos maravilhosos de êxtase, mas também o mais assombroso temor e respeito (JUNG, 2007).

O filho mais velho é o ego ferido. Enquanto estava sozinho com seu pai, parecia amá-lo, mas quando o irmão ressurge, aparece outro $\mathrm{Eu}$ : demônio interno, indiferente, amoral. Estava confortável sob a proteção do pai. Um comportamento psicológico pueril, sem desenvolver o Self, emaranhado na sombra, deixando tudo à revelia. Parece ser o símbolo do ciúme como ferida do ego. O filho mais velho está envolto pela sombra ameaçadora, criminosa. Ele quer fugir do pai amoroso, mas não poderá viver indefinidamente sob as picadas das mágoas. O Self é induzido a despertar sob a intercessão dos sentimentos de nobreza que renascem no íntimo, como divina herança da sua procedência. Na vida humana, cada momento tem seu sentido profundo, o seu significado essencial, a sua magia. 
O filho mais jovem iluminou o ego com a consciência de si, reconheceu o erro, renovouse pela humilhação que o engrandeceu; ademais, liberou das estruturas profundas do inconsciente as paixões da vingança, da maldade. A situação remete à Erínia mitológica encarregada de ferir Sísifo, conduzindo a pedra para o topo da montanha, de onde ela escapa e rola abaixo, compondo o conflito.

Sabendo-se não estar esgotada a análise de vários símbolos da parábola exposta, passa-se a algumas discussões.

\section{Discussão}

Jung (2011b) expressa que determinadas semelhanças entre a teologia régia egípcia, babilônica, grega, romana e judaica e o cristianismo trazem um trato com a natureza psíquica do homem, observando e sentindo as manifestações do inconsciente. A estrutura psicológica da personalidade humana tem na religião, nos heróis, nos mitos, nos símbolos e nas artes um fenômeno sociológico/histórico na vida do ser humano enquanto formação do mundo.

Assim, Jung fundamentou a Psicologia Analítica para atender às necessidades profundas do ser humano, procurando despertá-lo para a sua realidade transcendental e trabalhando os valores nobres adormecidos que ele, ser humano, consegue identificar com a vida. Nesse sentido, o equilíbrio mente/corpo/emoção é essencial, favorecendo o ser humano com a harmonia das aquisições diárias sobre os conflitos, a diluição destes mediantes a aquiescência dos sentimentos em perfeita identificação com o Self (JUNG, 2006).

Ao analisar a parábola "A volta do filho pródigo" e a tela de Rembrandt, que retrata a narrativa com maestria, infere-se que, em que pese o filho pródigo não tenha aparentemente saído de casa com o propósito (consciente) de praticar um ato heroico ou de buscar por algo grandioso - ele simplesmente queria liberdade para viver e gastar com prazeres o que recebeu -, essa mobilização de energia que serve a vida remete ao herói arquetípico apontado pela teoria da Psicologia
Analítica. Tal mobilização do filho pródigo em ceder à sombra, à não responsabilidade, à violência do abandono do pai idoso, à exuberância de egotismo, ao desprezo pelo irmão mais velho - que trabalha - e ao gozo do prazer, da irresponsabilidade e da incontinência moral representa a busca de destruição dos demônios do desespero e da depressão (HOLLIS, 1997, p. 54) e, ao final, da reconciliação.

Segundo a teoria, essa viagem para longe é, de certo modo, uma busca arquetípica de heroísmo, de conquista do desconhecido, de infinito. Percebe-se que é o papel que a sombra faz na natureza humana ao reconhecê-la. Esse aspecto sombrio torna-se característica necessária ao pleno desenvolvimento do homem, ou seja, a sombra também exerce outro papel. Ela possui um aspecto positivo, pois é responsável pela espontaneidade, pela criatividade, pelo insight e pela emoção profunda.

A parábola poderia ser de dois filhos ingratos, reunidos pelo amor sob o mesmo manto protetor do pai, ligando-os pelo anel da família, traço de união com toda a humanidade. A família provém do clã primitivo, do grupo animal, sendo um arquétipo de grande força psicológica, pois desestruturá-la é também desnortear-se.

Alvarez (2018) considera que Jesus conheceu com profundidade a psique humana, seus abismos, incertezas, equívocos e heranças. Portanto, busca-se na Parábola do Filho Pródigo o eficiente processo psicoterapêutico para as gerações do futuro. Assim, a análise da parábola traz uma reflexão sobre o amor e sobre a compaixão para libertar traumas e ressentimentos e contribui para a plenitude interior dos indivíduos, principalmente quando se compreende que complexo, para Jung (2006, 2007, 2008a), é um agrupamento de pensamentos, imagens e/ou ideias carregadas de intensa carga de emoções afetivas, memórias congeladas e reprimidas de momentos traumáticos. São conteúdos que perturbam a consciência, emergindo do inconsciente para a consciência.

Desse modo, o complexo paterno é ponto relevante no presente estudo. Os mitos paternos são 
revelados na Psicologia Analítica como modelos simbólicos de pai, construídos na civilização ocidental, os quais orientam inconscientemente a conduta da paternidade (JUNG, 2003).

A parábola e a tela descrevem os aspectos identificados no mito de Cronos, bem como apresentam alguns outros complexos: materno, de inferioridade e até de superioridade. No mito de Cronos isso se torna perceptível quando se compreende a simbologia de matar o pai, pois esse ato remete ao entendimento de que se está adquirindo uma liberdade para que se possa crescer, reinar, tornar-se adulto inteiro, liberto da dependência dos pais e, na sequência, reconciliarse com eles. A ruptura é para o crescimento físico, moral, intelectual, psicológico; não é o fim da jornada. Ao contrário, voltar inteiro para a origem é manter uma mente saudável, equilibrada.

A parábola igualmente remete aos aspectos expostos. Não aceitar os complexos de pai e mãe dentro de si mesmo, com todas as suas qualidades e defeitos, é rejeitar parte de si mesmo, originando inúmeros conflitos emocionais que impossibilitam uma vida plena. A conciliação simbólica não significa que se tenha que conviver com pai ou mãe ou irmão que geram/geraram muita dor, sofrimento. Significa integrar dentro de si mesmo a libertação da submissão, da autoridade/autoritarismo, da dependência, para viver plenamente a vida adulta, ou seja, integrar a sombra e viver o Self (BARCELLOS, 2009). Entende-se que, desse modo, o homem se torna ele mesmo, um ser completo, composto de consciente e inconsciente.

Assim, é possível perceber no conto, na parábola e na tela a religiosidade, os mitos, os heróis interligados/entrelaçados com a Psicologia Analítica. A parábola demonstra um processo de individuação, em que há um arquétipo da fratia, já que parece ser um campo de atualização de experiências afetivas entre irmãos com irmãos, irmãos/filhos e pais. Além disso, apresenta que o relacionamento com um irmão constrói a fundação emocional para outros relacionamentos horizontais de intimidade estabelecidos na vida adulta. Por fim, traz para a individuação as duras tarefas de reconstruir ou reelaborar as relações com a parentela corporal e espiritual.

\section{Considerações Finais}

Sob a ótica da Psicologia Analítica, o indivíduo pode assumir ora a personalidade do filho pródigo, ora a do irmão ciumento. O pai, por sua vez, tem dificuldade em ser o genitor compreensivo, dedicado, que reúne os dois filhos, ambos necessitados, sob o manto da bondade, da compreensão.

A parábola poderia ser concluída elucidando que o pai devotado levou o filho ressentido para dentro de casa. Uma viagem interna ao encontro do Self, aproximando-o do irmão arrependido, um Caim ressuscitado. Pai e filho olharam-se, superando distâncias emocionais em um demorado abraço de integração dos dois eus (egos), o eu do pai e o eu do filho, num Self coletivo, rico de valores, sentimentos morais, entre lágrimas que limparam as mazelas, as heranças lamentáveis do ego soberbo, primário.

Ao estudar Jung pode-se afirmar que uma pessoa não existe sem que tenha convivido com ao menos um ser masculino que assuma a imagem do pai enquanto provedor. Ou seja, a imagem do pai encontra-se no universo dos arquétipos. As relações de rivalidade entre irmãos estão presentes em várias culturas, em diferentes períodos da história humana, o que permite afirmar que este tema se trata de um arquétipo, imagens universais que existiram desde os tempos mais remotos, ou seja, conteúdos do inconsciente coletivo herdados de nossos antepassados, imagens ancestrais simbólicas presentes em mitos, lendas pertencentes a todos os indivíduos de todas as épocas.

Desse modo, conclui-se o estudo com essas considerações, consciente de que se trata de uma parábola que ainda tem muito a ser explorada no contexto da Psicologia Analítica. 


\section{Referências}

ALVARENGA, M. Z. Mitologia simbólica: estruturas da psique e regências míticas. São Paulo: Casa do Psicólogo, 2007.

ALVAREZ, R. Jesus: o homem mais amado da História. Rio de Janeiro: LeYa, 2018.

BARCELLOS, G. Oirmão: psicologia do arquétipo fraterno. Petrópolis: Vozes, 2009.

BATISTA, R. S. Sobre Carl G. Jung. Revista Brasileira de Educação Médica, Rio de Janeiro, v. 38, n. 3, p. 409-412, 2014.

BÍBLIA. Bíblia sagrada. Disponível em: https:// bibliaonline.com.br/acf/lc/15. Acesso em: 16 jul. 2018 .

BULL, D. et al. Rembrandt-Caravaggio. Amsterdam: Rijksmuseum, 2006.

CAVALCANTE, R. O casamento do Sol com a Lua. São Paulo: Círculo do Livro, 1992.

CAVALCANTE, R. O mundo do pai: mitos, símbolos e arquétipos. São Paulo: Cultrix, 1995.

CHEVALIER, J.; GHEERBRANT, A. Dicionários de símbolos. Rio de Janeiro: José Olympio, 1996.

DRIESSEN, C. Rembrandts vrouwen. Amsterdam: Bert Bakker, 2012.

DUARTE, A. J. O. Ecologia da alma: a natureza na obra científica de Carl Gustav Jung. Junguiana, São Paulo, v. 35, n. 1, p. 5-19, 2017.

GEWEHR, R. B. Entre filosofia e ciência: o problema do naturalismo na psicologia de Carl G. Jung. Psicologia USP, São Paulo, v. 30, p. 1-12, 2019.

HOLLIS, J. Sob a sombra de Saturno a ferida e a cura dos homens. São Paulo: Paulus, 1997.

HUISMAN, D. Dicionário de filósofos. São Paulo: Martins Fontes, 2001.

JUNG, C. G. A natureza da psique. Petrópolis: Vozes, 2013. (Obra Completa de C. G. Jung, v. 8, pt. 2).

JUNG, C. G. Aion: estudo sobre o simbolismo do si-mesmo. Petrópolis: Vozes, 2011a. (Obra Completa de C. G. Jung, v. 9, pt 2).
JUNG, C. G. Civilização em transição. Petrópolis: Vozes, 2001. (Obra Completa de C. G. Jung, v. 10, pt. 3).

JUNG, C. G. Espiritualidade e transcendência. Petrópolis: Vozes, 2011 b.

JUNG, C. G. Memórias, sonhos e reflexões. Rio de Janeiro: Nova Fronteira, 2006.

JUNG, C. G. O eu e o inconsciente. Petrópolis: Vozes, 2011c. (Obra Completa de C. G. Jung, v. 7, pt. 2).

JUNG, C. G. O homem e seus símbolos. Petrópolis: Vozes, 2008a.

JUNG, C. G. Os arquétipos e o inconsciente coletivo. Petrópolis: Vozes, 2003. (Obra Completa de C. G. Jung, v. 9, pt. 1).

JUNG, C. G. Psicologia do inconsciente. Petrópolis: Vozes, 1999. (Obra Completa de C. G. Jung,, v. 7, pt. 1).

JUNG, C. G. Psicologia e religião. Petrópolis: Vozes, 2007. (Obra Completa de C. G. Jung, v. 11, pt. 1).

JUNG, C. G. Símbolo da transformação. Petrópolis: Vozes, 2011d. (Obra Completa de C. G. Jung, v. 11, pt. 3).

JUNG, C. G. Tipos psicológicos. Petrópolis: Vozes, 2008b. (Obra Completa de C. G. Jung, v. 6).

JUNG, C. G. Estudos sobre psicologia analítica. Petrópolis: Vozes, 1981.

MINAYO, M. C. S. O desafio do conhecimento: pesquisa qualitativa em saúde. 12. ed. São Paulo: Hucitec-Abrasco, 2010.

MIRANDA, P. O numinoso e a experiência religiosa na psicologia de Carl Jung. Diálogos Junguianos, Brasília, v. 3, n. 1, p. 12-35, 2018. Disponível em: https://bit.ly/2WCpfwT. Acesso em: 9 jul. 2018.

OTTO, R. O sagrado: os aspectos irracionais na noção do divino e sua relação com o racional. São Paulo: Vozes, 2007. 
PENNA, E. M. D. Processamento simbólicoarquetípico: pesquisa em psicologia analítica. São Paulo: EDUC: FAPESP, 2015.

PENNA, E. M. D. Um estudo sobre o método de investigação da psique na obra de C. G. Jung. 2003. Dissertação (Mestrado em Psicologia) Pontifícia Universidade Católica de São Paulo, São Paulo, 2003.

PERES, L. M. V.; BARROS, R. M. K; ZANELLA, A. K. A imagem do arquétipo mestre-aprendiz que produziram marcas significativas: uma abordagem junguiana nas histórias de vida. Revista@mbienteeducação, São Paulo, v. 12, n. 2, p. 72-87, 2019.

REMBRANDT, $\mathrm{H}$. van $\mathrm{R}$. The return of the prodigal son. [1662?]. Oil on canvas, $262 \mathrm{x}$ $206 \mathrm{~cm}$. Disponível em: https://bit.ly/2z1hoQo. Acesso em: 16 jul. 2018.

SILVA JÚNIOR, R. C. O conceito junguiano de símbolo desde seus primórdios. 2009. Dissertação (Mestrado em Psicologia Clínica e Cultura) Universidade de Brasília, Brasília, 2009.

SILVEIRA, N. Jung: vida e obra. Rio de Janeiro: Paz e Terra, 2003.

SLIVE, S. Dutch painting: 1600-1800. New Haven: Yale University Press, 1995.

STEIN, M. Jung: o mapa da alma. São Paulo: Cultrix, 2016.

SVETlAnA, A. O projeto de Rembrandt. São Paulo: Companhia das Letras, 2010.

TOMMASI, S. B.; SOARES, L. F. M. O herói nos mitos gregos. Rio de Janeiro: Wak, 2015.

WHITMONT, E. C. A busca dos símbolos: conceitos básicos de Psicologia Analítica. São Paulo: Cultrix, 1995.

XAVIER, M. O conceito de religiosidade em Carl G. Jung. Revista Psico, Porto Alegre, v. 37, n. 2, p. 183-187, 2016. 
Ramos, L. F. C.; Tommasi, S. M. B. 